\title{
Catalytic asymmetric radical-polar crossover hydroalkoxylation
}

\author{
Christopher A. Discolo ${ }^{\ddagger}$, Eric E. Touney ${ }^{\ddagger}$, and Sergey V. Pronin ${ }^{*}$ \\ Department of Chemistry, University of California, Irvine, California 92697-2025, United States
}

Supporting Information Placeholder

\begin{abstract}
Asymmetric intramolecular hydrofunctionalization of tertiary allylic alcohols is described. This metal hydride-mediated catalytic radical-polar crossover reaction delivers corresponding epoxides in good to high enantioselectivity and constitutes the first example of asymmetric hydrogen atom transfer-initiated process. A series of modified cobalt salen complexes has proven optimal for achieving good efficiency and asymmetric induction. Experimental data suggest that cationic cobalt complexes may be involved in the enantio-determining step, where cation $-\pi$ interactions in the catalyst contribute to the asymmetric induction.
\end{abstract}

Metal hydride-initiated radical reactions serve as a highly chemoselective means for Markovnikov hydrofunctionalization of alkenes under mild conditions. ${ }^{1,2}$ The intermediate carbon-centered radicals generated upon hydrogen atom transfer (HAT) ${ }^{3}$ to a carbon-carbon double bond can react with atom and group transfer reagents, ${ }^{4}$ undergo addition to multiple bonds, ${ }^{5}$ and participate in cross-coupling reactions ${ }^{6}$ to introduce new functional groups and structural motifs. However, corresponding stereoselective processes are represented almost exclusively by the instances of stereochemical relay, including examples of auxiliary-controlled hydration and hydrohydrazination of $\alpha, \beta$-unsaturated amides. ${ }^{2,7}$ These limitations are not surprising due to the inherent challenge associated with enantiodifferentiation in prochiral alkyl radical intermediates. ${ }^{8}$ In this context, early reports of a highly selective cis addition of putative cobalt(III) hydride intermediates ${ }^{9}$ to 1,2-disubstituted alkenes involving rapid collapse of a radical pair in a solvent cage constitute the only relevant instances of efficient stereocontrol. ${ }^{10,11}$ Here we show the first example of a highly enantioselective HAT-initiated hydrofunctionalization (Figure 1). This radical-polar crossover process is catalyzed by a series of modified cobalt salen complexes and allows for conversion of tertiary allylic alcohols to the corresponding enantioenriched epoxides. We present data suggesting that cationic cobalt complexes may be involved in the enantio-determining step,

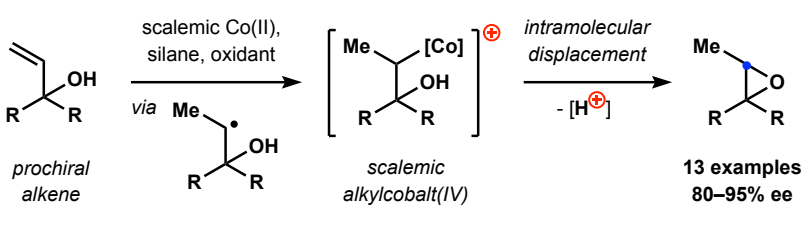

Figure 1. Catalysis by alkylcobalt(IV) complexes allows for efficient asymmetric induction in HAT-initiated hydrofunctionalizations.

where cation $-\pi$ interactions in the catalyst contribute to the asymmetric induction. We also demonstrate the application of this chemistry in a formal Markovnikov hydrofunctionalization of tertiary allylic alcohols for enantioselective installation of trisubstituted stereocenters including those bearing amine, sulfide, and nitrile functionalities.

Building on the earlier work in the field, ${ }^{12}$ we recently reported HAT-initiated radical-polar crossover reactions of tertiary allylic alcohols that afforded corresponding epoxides and semipinacol rearrangement products. ${ }^{13}$ In that setting, the outcome of the hydrofunctionalization event was under strong catalyst control, which suggested participation of alkylcobalt complexes as electrophilic intermediates. ${ }^{14}$ We reasoned that a proper choice of a scalemic chiral catalyst would allow for efficient enantioinduction provided that generation of the product could be limited to the putative alkylcobalt-based pathway. Initial experiments with tetrahydropyran derivative $\mathbf{1}$ and enantioenriched complex 4, which had previously proven competent in the HAT-initiated synthesis of epoxides, ${ }^{13}$ delivered product 2 with low but measurable enantiomeric excess (Table 1). Extensive experimentation with modifications in the ethylenediamine-derived fragment led to identification of a series of $o$-biarylsubstituted complexes that delivered the desired product with improved levels of asymmetric induction. Thus, application of complex 5 delivered epoxide $\mathbf{2}$ with moderate enantioenrichment. Introduction of extended aromatic motifs in the $o$-biaryl substituent (e.g., complexes 6 and 7) allowed for significant enhancement of enantioselectivity and a complementary increase in the efficiency. Ultimately, dibenzofuran-containing complex $\mathbf{8}$ 
Table 1. Effect of the Catalyst Structure on the Enantioenrichment and Yield of Epoxide $2^{\mathrm{a}, \mathrm{b}}$

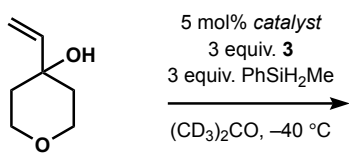

1<smiles></smiles>

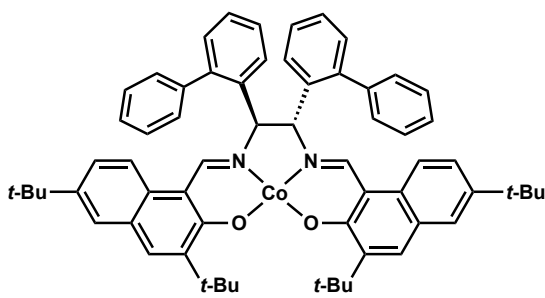

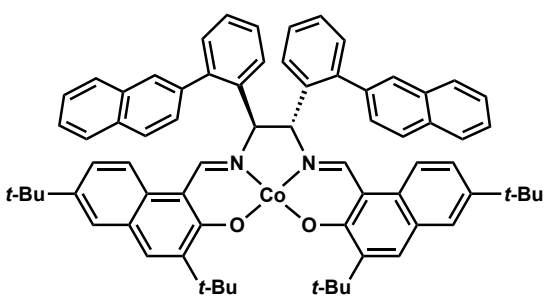

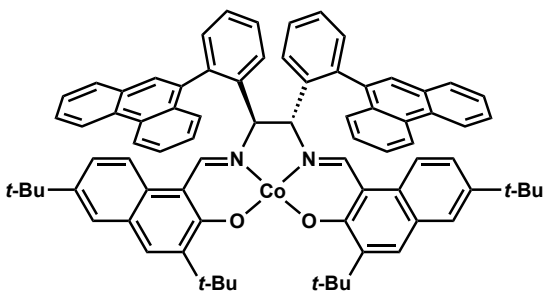

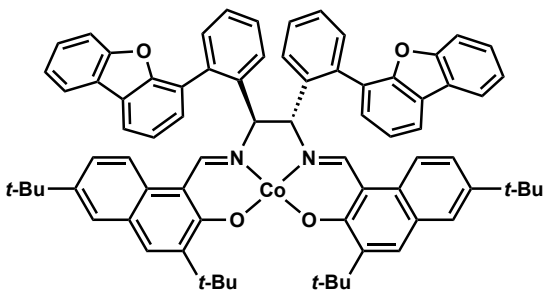

${ }^{\mathrm{a}}$ Reaction time was $18 \mathrm{~h}$, catalysts $\mathbf{4}-\mathbf{8}$ were $\geq 95 \%$ ee; see SI for details. ${ }^{b}$ Yields were based on internal standard and determined by ${ }^{1} \mathrm{H}$ NMR, see SI for details. ${ }^{\mathrm{c}} \mathrm{Re}-$ action with $0.5 \mathrm{~mol} \%$ of catalyst 8 afforded $51 \%$ yield (65\% conversion of alcohol 1) after $48 \mathrm{~h}$.

demonstrated optimal performance among the evaluated catalysts. ${ }^{15}$ The process could also be conducted at low catalyst loadings without detrimental effects on the enantioselectivity, but required extended reaction times to achieve appreciable conversion of alcohol $\mathbf{1}$.

Brief exploration of the substrate scope identified a
Table 2. Preliminary Substrate Scope of the HAT-Initiated Enantioselective Hydrofunctionalization ${ }^{\mathrm{a}}$
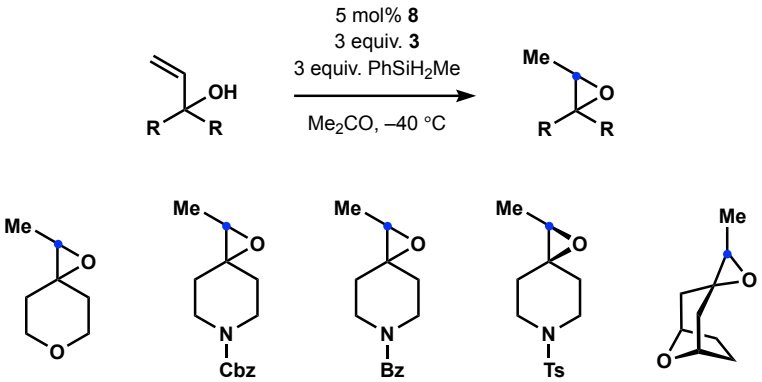

10

11

12

$(69 \%, 95 \% \text { ee })^{b, c, d} \quad(71 \%, 89 \% \text { ee })^{b} \quad(68 \%, 87 \% \text { ee })^{b} \quad(58 \%, 95 \% \text { ee })^{b, e} \quad(65 \%, 93 \% \text { ee })^{f, g}$
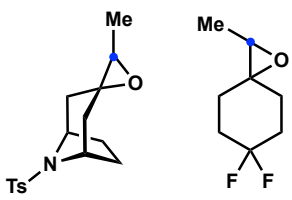<smiles>CC1OC12CCC(=O)CC2</smiles><smiles>CC1OC12CCC1(CC2)OCC(C)(C)CO1</smiles><smiles>CC(C)C1(O)CCC2(CC1)OC2C</smiles>

13 $14 \quad 15$ 16 $(51 \%, 80 \% \text { ee })^{f} \quad(52 \%, 88 \% \text { ee })^{\mathrm{c}, \mathrm{h}} \quad(56 \%, 89 \% \text { ee })^{\mathrm{b}} \quad(75 \%, 82 \% \text { ee })^{\mathrm{f}, \mathrm{g}} \quad(51 \%, 86 \% \text { ee })^{\mathrm{f}, \mathrm{g}}$
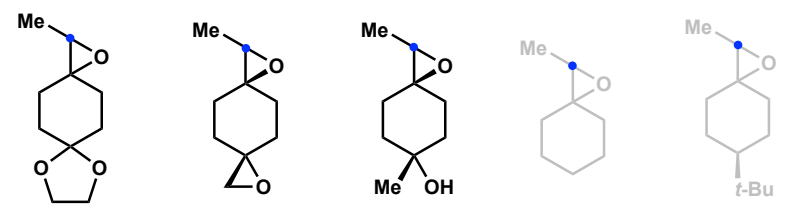

18
$(61 \%, 91 \% \text { ee })^{f, g}$ 19 20 21 22 $58 \%$ ee
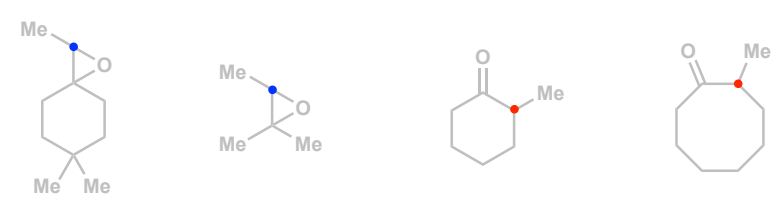

23
$(47 \%, 34 \% \text { ee })^{c, f}$ 24
$(79 \%, 6 \% \text { ee })^{c, f}$ $\mathbf{2 5}$
$(89 \%, 25 \% \text { ee })^{\mathrm{c}, \mathrm{f}, \mathrm{i}}$ $\mathbf{2 6}$
$(60 \%, 14 \% \text { ee })^{\mathrm{c}, \mathrm{f}, \mathrm{i}}$

${ }^{\mathrm{a}} 0.05 \mathrm{M}$ of allylic alcohol; see SI for details. ${ }^{\mathrm{b}}$ Reaction time was $18 \mathrm{~h}$. ${ }^{c}$ Yields were based on internal standard and determined by ${ }^{1} \mathrm{H}$ NMR. ${ }^{\mathrm{d}}$ Yield of isolated material for characterization purposes was $48 \%$. ${ }^{\mathrm{e}}$ Absolute configuration was determined by X-ray crystallographic analysis. ${ }^{\mathrm{f}}$ Reaction time was $48 \mathrm{~h} .{ }^{\mathrm{g}} \mathrm{At}-60{ }^{\circ} \mathrm{C}$. ${ }^{\mathrm{h}}$ Yield of isolated material for characterization purposes was $38 \%$. ${ }^{\mathrm{i}}$ Epoxide was not observed.

series of cyclic dialkyl(vinyl)carbinols that successfully participated in our enantioselective HAT-initiated hydrofunctionalization. Thus, derivatives of tetrahydropyran and piperidine (products 2, Table 1, and 9-11, Table 2) and their bicyclic counterparts (products 12 and 13) underwent conversion to the corresponding epoxides with good to high levels of asymmetric induction. Singlecrystal X-ray analysis of product $\mathbf{1 1}$ established the absolute configuration of the newly formed stereocenter to be $R$, which is likely shared with other enantioenriched epoxides obtained in this study. Similarly good perfor- 
mance was observed with various functionalized cyclohexanes (products 14-20). Simple cyclohexanes including those containing only alkyl substituents (products 21-23) produced low to moderate degrees of enantioinduction. Application of acyclic substrates was unsuccessful (e.g., product 24). Attempted reactions of cycloalkanols containing five- and seven-membered rings led to the corresponding semipinacol rearrangement products (e.g., 25 and 26), ${ }^{16}$ which were produced with low levels of stereocontrol.

Analysis of the differential activation parameters in the hydrofunctionalization of allylic alcohol $\mathbf{1}$ in the presence of catalysts 5-8 revealed that enantioselectivity was enthalpically controlled and the magnitude of differential enthalpy correlated positively with the expanse of the aromatic moieties (Table 3). ${ }^{17}$ This enthalpic gain

Table 3. Eyring Analysis of Enantioselectivity in the Hydrofunctionalization of Allylic Alcohol $1^{\text {a }}$

\begin{tabular}{|c|c|c|c|}
\hline & $\begin{array}{r}5 \text { mol\% ca } \\
3 \text { equiv } \\
3 \text { equiv. } \mathrm{Ph}\end{array}$ & & $\stackrel{\text { Me }}{\Theta_{\text {OTf }}}$ \\
\hline & $\left(\mathrm{CD}_{3}\right)_{2}$ & & \\
\hline catalyst & $R$-squared & $\Delta \Delta H^{\ddagger}(\mathrm{kcal} / \mathrm{mol})$ & $\Delta \Delta S^{\ddagger}(\mathrm{cal} / \mathrm{mol} \cdot \mathrm{K})$ \\
\hline 5 & 0.98 & $-1.82 \pm 0.07$ & $-4.9 \pm 0.2$ \\
\hline 6 & 0.99 & $-3.28 \pm 0.07$ & $-9.5 \pm 0.2$ \\
\hline 7 & 0.99 & $-5.38 \pm 0.27$ & $-17.2 \pm 0.9$ \\
\hline 8 & 0.99 & $-6.54 \pm 0.23$ & $-20.7 \pm 0.7$ \\
\hline
\end{tabular}

${ }^{\mathrm{a} B a s e d}$ on six data points per catalyst, $\mathrm{T}=233-292 \mathrm{~K}$, see SI for details.

was attenuated by the corresponding increase in the differential entropy terms observed across the series of catalysts 5-8. These data are in principle consistent with a simple steric explanation that increasing the size of the arene fragment leads to destabilization of the minor transition state assembly in the enantio-determining step. However, current understanding of the electronic structure of relevant cobalt complexes also suggests an intriguing possibility for the role of stabilizing non-covalent interactions in the observed effects. Previous spectroscopic and computational studies of alkylcobalt(IV) glyoximates, porphyrins, and corrins as well as cobalt(III) salen derivatives indicate that radical cations resulting from ligand-to-metal charge transfer can contribute to the electronic structure. ${ }^{18,19}$ We therefore proposed that cationic cobalt complexes may experience cation $-\pi$ interactions between the radical cation of the salen motif and the biaryl substituents of the ethylenediamine-based fragment (Figure 2). ${ }^{20}$ In this setting, extension of the participating arenes would lead to more stabilizing interactions and their energetic benefits would be manifested enthalpically. ${ }^{21}$ We found that enantioselectivity correlated strongly with both the polarizability and the quadrupole moment of the aromatic hydrocarbons correspon-

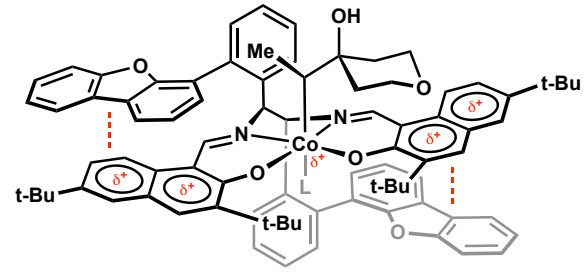

Figure 2. Representation of a radical cation of the putative alkylcobalt(IV) intermediate derived from catalyst 8 and substrate $\mathbf{1}$ ( $\mathbf{L}$ is likely to be solvent). Red dotted lines indicate the proposed cation $-\pi$ interactions between the radical cation of the salen motif and the biaryl substituents.

ding to the varied substituents in complexes 5-7. ${ }^{22}$ Since the strength of cation $-\pi$ interactions should primarily be a function of electrostatic and dispersion forces, ${ }^{23,24}$ the observed correlations between the underlying physical properties and the degree of asymmetric induction suggest that cation $-\pi$ interactions contribute to the improved stereochemical outcomes. Should the effect of the substituents be largely steric in nature, such significant correlations would not be expected. ${ }^{17,25}$ This proposal is also consistent with the observation that introduction of electron-rich arenes results in additional enhancement of enantioselectivity (e.g., compare complexes 7 and 8). ${ }^{26}$ We note that continued expansion of the aromatic moieties (e.g., introduction of pyrenyl and triphenylenyl groups) becomes detrimental to the performance of the catalyst. We attribute this effect to increasing steric interactions between the biaryl fragments and the bulky tert-butyl substitutents of the hydroxynaphthaldehyde-derived motif, which could lead to disruption of the cation $-\pi$ interactions.

Analysis of structural features found in the wellperforming allylic alcohols (see Table 2) revealed additional correlations. The presence of properly positioned heteroatom-containing substituents appears to result in superior enantioselectivity during the epoxide formation. For example, functionalized epoxides 18-20 were produced with good enantioselectivities. ${ }^{27}$ In contrast, epoxides 21-23 were obtained with significantly lower asymmetric induction under identical conditions, suggesting that steric factors are not the sole determinant in enantioselectivity. The superior outcomes observed with products 18-20 may stem from additional stabilizing interactions between the functionalized cyclohexane fragment and the radical cation of the cobalt salen motif in the enantio-determining step. Similar considerations

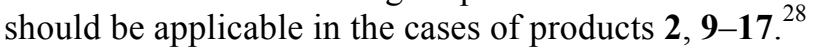

Taken all together, these observations suggest involvement of cationic cobalt complexes in the enantiodetermining step. For example, diastereomeric alkylcobalt(IV) intermediates may undergo kinetic resolution ${ }^{29}$ during the intramolecular nucleophilic displacement (see equation 1). In this scenario, an increase in the cation- $\pi$ interactions in the catalyst would stabilize the electrophiles, leading to a later transition state and enhanced 

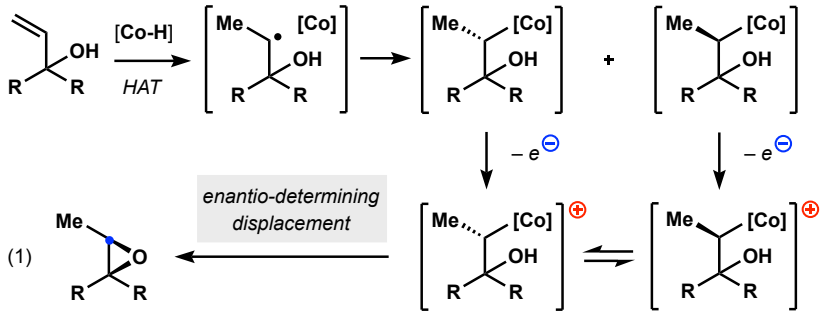

enantioselectivity. Additional interactions between the heteroatom-containing substituents of the wellperforming substrates and the radical cation of the salen motif would have a similar effect on the displacement. Diastereomeric alkylcobalt(IV) intermediates may interconvert upon epimerization of the stereocenter bearing the homolytically-labile carbon-cobalt bond. ${ }^{30}$ Relevant rearrangements of alkyl substituents in organocobalt complexes were previously demonstrated to proceed via a radical chain mechanism. ${ }^{31}$ Formation of alkylcobalt(IV) intermediates may involve oxidation of the corresponding alkylcobalt(III) complexes ${ }^{14}$ which can be generated via HAT from the putative cobalt(III) hydride intermediates to alkenes followed by radical pair collapse. ${ }^{32,33}$ An alternative scenario may involve enantiodetermining diffusion of alkyl radicals into the solvent cage during the capture by cationic cobalt(III) complexes en route to the corresponding alkylcobalt(IV) intermediates. ${ }^{34-36}$ Both scenarios are also consistent with the superior performance of polar solvents: cyclization of allylic alcohol $\mathbf{1}$ in the presence of catalyst $\mathbf{8}$ produces epoxide 2 only in $26 \%$ ee when acetone is replaced with dichloromethane.

Combination of our HAT-initiated cyclization of dialkyl(vinyl)carbinols with the well-established reactivity of trisubstituted epoxides in $\mathrm{S}_{\mathrm{N}} 2$ reactions provides an entry into a formal enantioselective hydrofunctionalization of tertiary allylic alcohols with Markovnikov selectivity. Thus, reaction of epoxide 11 with Boc-protected piperazine produced aminoalcohol 27 in high yield (Scheme 1). Related structural motifs previously found

\section{Scheme 1. Derivatization of Epoxide 11}
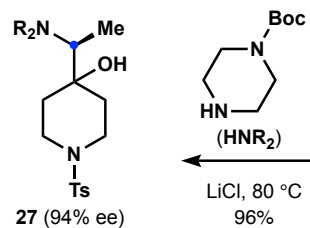

$\mathrm{PhS} \mathrm{Me}^{\mathrm{Me}}$

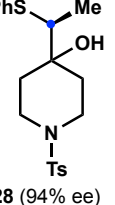
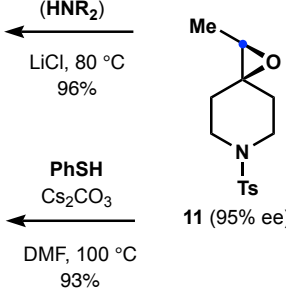

$93 \%$

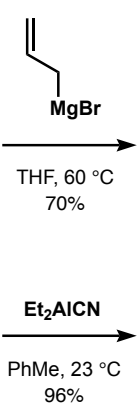

$96 \%$

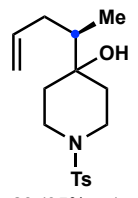

$29(95 \%$ ee)

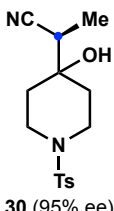

application in medicinal chemistry efforts. ${ }^{37}$ Similar displacements with a thiolate, an allyl Grignard reagent,and Nagata's reagent delivered corresponding sulfide 28, alkene 29, and nitrile 30, respectively, with good effi- ciency. In all cases, excellent levels of stereoinversion were observed, demonstrating potential of this approach in the enantioselective synthesis of polyfunctional building blocks.

In summary, we show the first example of a highly enantioselective HAT-initiated hydrofunctionalization catalyzed by a series of new cobalt salen complexes. Our observations are consistent with the proposed participation of alkylcobalt(IV) complexes, which accounts for strong catalyst control and allows for direct conversion of dialkyl(vinyl)carbinols to the corresponding scalemic epoxides. The experimental data suggest that cationic cobalt complexes may be involved in enantiodetermining step, where cation- $\pi$ interactions in the catalyst contribute to the superior asymmetric induction obtained with the new cobalt salen derivatives. The radical-polar crossover reactivity described herein is expected to serve as a starting point for overcoming the challenges of absolute stereocontrol in the development of asymmetric HAT-initiated processes and for future studies of the mechanistic underpinnings associated with this fascinating class of chemical transformations. ${ }^{38}$

\section{ASSOCIATED CONTENT}

Experimental procedures, characterization data for new compounds, and CIF file for compound 11. This material is available free of charge via the Internet at http://pubs.acs.org.

\section{AUTHOR INFORMATION}

\section{Corresponding Author}

spronin@uci.edu

\section{Author Contributions}

"These authors contributed equally. Notes

The authors declare no competing financial interest.

\section{ACKNOWLEDGMENT}

Financial support for this work was provided by the NSF (CAREER CHE-1848076). Acknowledgment is made to the Donors of the American Chemical Society Petroleum Research Fund for partial support of this research (PRF 58063-DNI1). Funding from the School of Physical Sciences at the University of California Irvine and the Chao Family Comprehensive Cancer Center is also gratefully acknowledged. We thank Professors Larry Overman, Chris Vanderwal, and Scott Rychnovsky for providing routine access to their instrumentation and helpful discussions. We also thank Professors Elizabeth Jarvo and Vy Dong for providing access to their SFC systems and Dr. Joseph Ziller and Daniel Huh for X-ray crystallographic analysis.

\section{REFERENCES}

(1) For an overview of pioneering work on relevant hydrofunctionalizations see: Mukaiyama, T.; Yamada, T. Recent advances in aerobic oxygenation. Bull. Chem. Soc. Jpn. 1995, 68, 17. 
(2) For recent reviews of the field see: (a) Crossley, S. W. M.; Martinez, R. M.; Obradors, C.; Shenvi, R. A. Mn, Fe, and Co-catalyzed radical hydrofunctionalizations of olefins. Chem. Rev. 2016, 116, 8912. (b) Green, S. A.; Crossley, S. W. M.; Matos, J. L. M.; VásquezCéspedes, S.; Shevick, S. L.; Shenvi, R. A. The high chemofidelity of metal-catalyzed hydrogen atom transfer. Acc. Chem. Res. 2018, 51, 2628.

(3) Shenvi and Herzon propose HAT as the initial step in their related hydrogenations: (a) Iwasaki, K.; Wan, K. K.; Oppedisano, A.; Crossley, S. W. M.; Shenvi, R. A. Simple, chemoselective hydrogenation with thermodynamic control. J. Am. Chem. Soc. 2014, 136, 1300. (b) King, S. M.; Ma, X.; Herzon, S. B. A method for the selective hydrogenation of alkenyl halides to alkyl halides. J. Am. Chem. Soc. 2014, 136, 6884. For similar mechanistic considerations see: (c) Eisenberg, D. C.; Norton, J. R. Hydrogen-atom transfer reactions of transition-metal hydrides. Isr. J. Chem. 1991, 31, 55.

(4) For selected examples see: (a) Waser, J.; Nambu, H.; Carreira, E. M. Cobalt-catalyzed hydroazidation of olefins: convenient access to alkyl azides. J. Am. Chem. Soc. 2005, 127, 8294. (b) Gaspar, B.; Carreira, E. M. Mild cobalt-catalyzed hydrocyanation of olefins with tosyl cyanide. Angew. Chem. Int. Ed. 2007, 46, 4519. (c) Gaspar, B.; Carreira, E. M. Catalytic hydrochlorination of unactivated olefins with para-toluenesulfonyl chloride. Angew. Chem. Int. Ed. 2008, 47, 5758. (d) Gaspar, B.; Carreira, E. M. Cobalt catalyzed functionalization of unactivated alkenes: regioselective reductive $\mathrm{C}-\mathrm{C}$ bond forming reactions. J. Am. Chem. Soc. 2009, 131, 13214. (e) Girijavallabhan, V.; Alvarez, C.; Njoroge, F. G. Regioselective cobaltcatalyzed addition of sulfides to unactivated alkenes. J. Org. Chem. 2011, 76, 6442. (f) Baker, T.; Boger, D. L. Fe(III)/ $\mathrm{NaBH}_{4}$-Mediated free radical hydrofluorination of unactivated alkenes. J. Am. Chem. Soc. 2012, 134, 13588. (g) Leggans, E. K.; Barker, T. J.; Duncan, K. K.; Boger, D. L. Iron(III)/ $/ \mathrm{NaBH}_{4}$-Mediated additions to unactivated alkenes: synthesis of novel 20 '-vinblastine analogues. Org. Lett. 2012, 14, 1428. (h) Shigehisa, H.; Nishi, E.; Fujisawa, M.; Hiroya, K. Cobalt-catalyzed hydrofluorination of unactivated olefins: a radical approach of fluorine transfer. Org. Lett. 2013, 15, 5158. (i) Ma, X. S.; Herzon, S. B. Non-classical selectivities in the reduction of alkenes by cobalt-mediated hydrogen atom transfer. Chem. Sci. 2015, 6, 6250. (j) Zheng, J.; Wang, D.; Cui, S. Fe-Catalyzed reductive coupling of unactivated alkenes with $\beta$-nitroalkenes. Org. Lett. 2015, 17, 4572. (k) Crossley, S. W. M.; Martinez, R. M.; Guevara-Zuluaga, S.; Shenvi, R. A. Synthesis of the privileged 8-arylmenthol class by radical arylation of isopulegol. Org. Lett. 2016, 18, 2620. (1) Ma, X.; Herzon, S. B. Intermolecular hydropyridylation of unactivated alkenes $\mathrm{J}$. Am. Chem. Soc. 2016, 138, 8718. (m) Ma, X.; Dang, H.; Rose, J. A.; Rablen P.; Herzon, S. B. Hydroheteroarylation of unactivated alkenes using $N$ methoxyheteroarenium salts. J. Am. Chem. Soc. 2017, 139, 5998. (n) Qi, J.; Zheng, J.; Cui, S. Fe(III)-Catalyzed hydroallylation of unactivated alkenes with Morita-Baylis-Hillman adducts. Org. Lett. 2018, 20, 1355. (o) Yang, L.; Ji, W.-W.; Lin, E; Li, J.-L; Fan, W.-X.; Li, Q.; Wang, H. Synthesis of alkylated monofluoroalkenes via Fe-catalyzed defluorinative cross-coupling of donor alkenes with gemdifluoroalkenes. Org. Lett. 2018, 20, 1924. (p) Zhang, Y.; Huang, C.; Lin, X.; Hu, Q.; Hu, B.; Zhou, Y.; Zhu, G. Modular synthesis of alkylarylazo compounds via iron(III)-catalyzed olefin hydroamination. Org. Lett. 2019, 21, 2261. (q) Zhou, X.-L.; Yang, F.; Sun, H.-L.; Yin, Y.-N.; Ye, W.-T.; Zhu, R. Cobalt-catalyzed intermolecular hydrofunctionalization of alkenes: evidence for a bimetallic pathway. $J$. Am. Chem. Soc. 2019, 141, 7250.

(5) For selected examples see: (a) Wang, L.-C.; Jang, H.-Y.; Roh, Y.; Lynch, V.; Schultz, A. J.; Wang, X.; Krische, M. J. Diastereoselective cycloreductions and cycloadditions catalyzed by $\mathrm{Co}(\mathrm{dpm})_{2}$ silane $(\mathrm{dpm}=2,2,6,6$-tetramethylheptane-3,5-dionate): mechanism and partitioning of hydrometallative versus anion radical pathways. $J$. Am. Chem. Soc. 2002, 124, 9448. (b) Waser, J.; Carreira, E. M. Convenient synthesis of alkylhydrazides by the cobalt-catalyzed hydrohydrazination reaction of olefins and azodicarboxylates. J. Am. Chem. Soc. 2004, 126, 5676. (c) Smith, D. M.; Pulling, M. E.; Norton, J. R. Tin-free and catalytic radical cyclizations. J. Am. Chem. Soc. 2007, 129, 770. (d) Hartung, J.; Pulling, M. E.; Smith, D. M.; Yang, D. X.; Norton, J. R. Initiating radical cyclizations by $\mathrm{H} \bullet$ transfer from transi- tion metals. Tetrahedron 2008, 64, 11822. (e) Lo, J. C.; Yabe, Y.; Baran, P. S. A practical and catalytic reductive olefin coupling. J. Am. Chem. Soc. 2014, 136, 1304. (f) Lo, J. C.; Gui, J.; Yabe, Y.; Pan, C.M.; Baran, P. S. Functionalized olefin cross-coupling to construct carbon-carbon bonds. Nature 2014, 516, 343. (g) Crossley, S. W. M.; Barabé, F.; Shenvi, R. A. Simple, chemoselective, catalytic olefin isomerization. J. Am. Chem. Soc. 2014, 136, 16788 (h) Kuo, J. L.; Hartung, J.; Han, A.; Norton, J. R. Direct generation of oxygenstabilized radicals by $\mathrm{H} \cdot$ transfer from transition metal hydrides. $J$. Am. Chem. Soc. 2015, 137, 1036. (i) Gui, J.; Pan, C.-M.; Jin, Y.; Qin, T.; Lo, J. C.; Lee, B. J.; Spergel, S. H.; Mertzman, M. E.; Pitts, W. J.; La Cruz, T. E.; Schmidt, M. A.; Darvatkar, N.; Natarajan, S.; Baran, P. S. Practical olefin hydroamination with nitroarenes. Science $\mathbf{2 0 1 5}$, 348, 886. (j) Dao, H. T.; Li, C.; Michaudel, Q.; Maxwell, B. D.; Baran, P. S. Hydromethylation of unactivated olefins. J. Am. Chem. Soc. 2015, 137, 8046. (k) Zheng, J.; Qi, J.; Cui, S. Fe-Catalyzed olefin hydroamination with diazo compounds for hydrazone synthesis. (1) Lo, J. C.; Kim, D.; Pan, C.-M.; Edwards, J. T.; Yabe, Y.; Gui, J.; Qin, T.; Gutiérrez, S.; Giacoboni, J.; Smith, M. W.; Holland, P. L.; Baran, P. S. Fe-catalyzed $\mathrm{C}-\mathrm{C}$ bond construction from olefins and radicals. $J$. Am. Chem. Soc. 2017, 139, 2484. (m) Saladrigas, M.; Bosch, C.; Saborit, G. V.; Bonjoch, J.; Bradshaw, B. Radical cyclization of alkenetethered ketones initiated by hydrogen-atom transfer. Angew. Chem. Int. Ed. 2018, 57, 182. (n) Saladrigas, M.; Lore, G.; Bonjoch, J.; Bradshaw, B. Coupling of alkenes with hydrazones: access to complex amines. ACS Catal. 2018, 8, 11699. (o) Matos, J. L. M.; Vásquez-Céspedes, S.; Gu, J.; Oguma, T.; Shenvi, R. A. Branch-selective addition of unactivated olefins into imines and aldehydes. $J$. Am. Chem. Soc. 2018, 140, 16976.

(6) (a) Green, S. A.; Matos, J. L. M.; Yagi, A.; Shenvi, R. A. Branch-selective hydroarylation: iodoarene-olefin cross-coupling $J$. Am. Chem. Soc. 2016, 138, 12779. (b) Green, S. A.; VásquezCéspedes, S.; Shenvi, R. A. Iron-nickel dual-catalysis: a new engine for olefin functionalization and the formation of quaternary centers $J$. Am. Chem. Soc. 2018, 140, 11317. (c) Shevick, S. L.; Obradors, C.; Shenvi, R. A. Mechanistic interrogation of $\mathrm{Co} / \mathrm{Ni}$-dual catalyzed hydroarylation. J. Am. Chem. Soc. 2018, 140, 12056. (d) Green, S. A.; Huffman, T. R.; McCourt, R. O.; van der Puyl, V.; Shenvi, R. A. Hydroalkylation of olefins to form quaternary carbons, J. Am. Chem. Soc. 2019, 141, 7709 .

(7) (a) Sato, M.; Gunji, Y.; Ikeno, T.; Yamada T. Stereoselective preparation of $\alpha$-hydroxycarboxamide by manganese complex catalyzed hydration of $\alpha, \beta$-unsaturated carboxamide with molecular oxygen and phenylsilane. Chem. Lett. 2004, 33, 1304. (b) Sato, M.; Gunji, Y.; Ikeno, T.; Yamada T. Stereoselective $\alpha$-hydrazination of $\alpha, \beta$ unsaturated carboxylates catalyzed by manganese(III) complex with dialkylazodicarboxylate and phenylsilane. Chem. Lett. 2005, 34, 316.

(8) For relevant discussion see: (a) Sibi, M. P.; Manyem, S.; Zimmerman, J. Enantioselective radical processes. Chem. Rev. 2003, 103, 3263. (b) Studer, A.; Curran, D. P. Catalysis of radical reactions: a radical chemistry perspective. Angew. Chem., Int. Ed. 2016, 55, 58. (c) Yan, M.; Lo, J. C.; Edwards, J. T.; Baran, P. S. Radicals: reactive intermediates with translational potential. J. Am. Chem. Soc. 2016, 138, 12692. (d) Lu, Q.; Glorius, F. Radical enantioselective C(sp3)-H functionalization. Angew. Chem., Int. Ed. 2017, 56, 49.

(9) Lacy, D. C.; Roberts, G. M.; Peters, J. C. The cobalt hydride that never was: revisiting Schrauzer's "hydridocobaloxime". J. Am. Chem. Soc. 2015, 137, 4860.

(10) (a) Jackman, L. M.; Hamilton, J. A.; Lawlor, J. M. Reactions of hydridopentacyanocobaltate with the anions of $\alpha, \beta$-unsaturated acids. J. Am. Chem. Soc. 1968, 90, 1914. (b) Gridnev, A. A.; Ittel, S. D.; Wayland, B. B.; Fryd, M. Isotopic investigation of hydrogen transfer related to cobalt-catalyzed free-radical chain transfer. Organometallics 1996, 15, 5116.

(11) For an early example of catalytic enantioselective HATinitiated reaction that proceeds in $28 \%$ ee see: Shigehisa, H.; Hayashi, M.; Ohkawa, H.; Suzuki, T.; Okayasu, H.; Mukai, M.; Yamazaki, A.; Kawai, R.; Kikuchi, H.; Satoh, Y.; Fukuyama, A.; Hiroya, K. Catalytic synthesis of saturated oxygen heterocycles by hydrofunctionalization of unactivated olefins: unprotected and protected strategies $J$. Am. Chem. Soc. 2016, 138, 10597. (found in Scheme 3b). 
(12) For pioneering work on HAT-initiated radical-to-cation crossover reactions see: (a) Shigehisa, H.; Aoki, T.; Yamaguchi, S.; Shimizu, N.; Hiroya, K. Hydroalkoxylation of unactivated olefins with carbon radicals and carbocation species as key intermediates. J. Am. Chem. Soc. 2013, 135, 10306. (b) Shigehisa, H.; Koseki, N.; Shimizu, N.; Fujisawa, M.; Niitsu, M.; Hiroya, K. Catalytic hydroamination of unactivated olefins using a Co catalyst for complex molecule synthesis. J. Am. Chem. Soc. 2014, 136, 13534. (c) See ref. 10. A radical-tocation crossover pathway is also proposed in a relevant hydroarylation of alkenes: (d) Shigehisa, H.; Ano, T.; Honma, H.; Ebisawa, K.; Hiroya, K. Co-Catalyzed hydroarylation of unactivated olefins $\mathrm{Org}$. Lett. 2016, 18, 3622.

(13) Touney, E. E.; Foy, N. J.; Pronin, S. V. Catalytic radical-polar crossover reactions of allylic alcohols. J. Am. Chem. Soc. 2018, 140, 16982.

(14) (a) Abley, P.; Dockal, E. R.; Halpern, J. Oxidative cleavage of cobalt-carbon bonds in organobis(dimethylg1yoximato)cobalt compounds J. Am. Chem. Soc. 1972, 94, 659. (b) Anderson, S. N.; Ballard, D. H.; Chrzastowski, J. Z.; Dodd, D.; Johnson, M. D. Inversion of configuration in the nucleophilic displacement of cobalt from alkylcobalt( IV) complexes and its relevance to the halogenation of the corresponding alkylcobalt(III) complexes J. Chem. Soc., Chem. Commun. 1972, 0, 685. (c) Halpern, J.; Chan, M. S.; Hanson, J.; Roche, T. S.; Topich, J. A. Detection and characterization of radical cations produced by one-electron chemical and electrochemical oxidations of organocobalt compounds J. Am. Chem. Soc. 1975, 97, 1606. (d) Halpern, J.; Topich, J.; Zamaraev, K. I. Electron paramagnetic resonance spectra and electronic properties of organobis(dimethylglyoximato)cobalt(IV) complexes. Inorganica Chim. Acta 1976, 20, L21. (e) Magnuson, R. H.; Halpern, J.; Levitin, I. Ya.; Vol'pin, M. E. Stereochemistry of the nucleophilic cleavage of cobalt-carbon bonds in organocobalt(IV) compounds J. Chem. Soc., Chem. Commun. 1978, 0, 44. (f) Topich, J.; Halpern, J. Organobis(dioximato)cobalt(IV) complexes: electron paramagnetic resonance spectra and electronic structures. Inorg. Chem. 1979, 18, 1339. (g) Halpern, J.; Chan, M. S.; Roche, T. S.; Tom, G. M. Redox chemistry of organobis(dimethylglyoximato)cobalt complexes. Acta Chem. Scan. A 1979, 33, 141.

(15) Corresponding hydrogenation products constituted the majority of the mass balance. See ref. $3 \mathrm{a}, \mathrm{b}$ for relevant hydrogenation processes.

(16) These observations are consistent with our previous studies. See ref. 13 for details.

(17) For a landmark example of Eyring analysis of enantioselectivity and its application to study cation $-\pi$ interactions in the context of enantioselective catalysis see: Knowles, R. R.; Lin, S.; Jacobsen, E. N. Enantioselective thiourea-catalyzed cationic polycyclizations. $J$. Am. Chem. Soc. 2010, 132, 5030.

(18) For examples of relevant alkylcobalt(IV) complexes that point to diversity of electronic structures see: (a) See ref. 14f. (b) Fukuzumi, S.; Miyamoto, K.; Suenobu, T.; Van Caemelbecke, E.; Kadish, K. M. Electron transfer mechanism of organocobalt porphyrins. Site of electron transfer, migration of organic groups, and cobalt-carbon bond energies in different oxidation states. J. Am. Chem. Soc. 1998, 120, 2880. (c) Harmer, J.; Van Doorslaer, S.; Gromov, I.; Bröring, M.; Jeschke, G.; Schweiger, A. A pulse EPR and ENDOR investigation of the electronic structure of a $\sigma$-carbon-bonded cobalt(IV) corrole. $J$. Phys. Chem. B 2002, 106, 2801. (d) Kumar, N.; Kuta, J.; Galezowski, W.; Kozlowski, P. M. Electronic structure of one-electron-oxidized form of the methylcobalamin cofactor: spin density distribution and pseudo-Jahn-Teller effect. Inorg. Chem. 2013, 52, 1762.

(19) For studies of relevant cobalt(III) salen complexes see: (a) Bar-Nahum, I.; Cohen, H.; Neumann, R. Organometallicpolyoxometalate hybrid compounds: metallosalen compounds modified by Keggin type polyoxometalates. Inorg. Chem. 2003, 42, 3677. (b) Kochem, A.; Kanso, H.; Baptiste, B.; Arora, H.; Philouze, C.; Jarjayes, O.; Vezin, H.; Luneau, D.; Orio, M.; Thomas, F. Ligand contributions to the electronic structures of the oxidized cobalt(II) salen complexes. Inorg. Chem. 2012, 51, 10557.

(20) For selected reviews of cation $-\pi$ interactions in chemical catalysis see: (a) Pluth, M. D.; Bergman, R. G.; Raymond, K. N. Proton- mediated chemistry and catalysis in a self-assembled supramolecular host. Acc. Chem. Res. 2009, 42, 1650. (b) Brown, C. J.; Toste, F. D.; Bergman, R. G.; Raymond, K. N. Supramolecular catalysis in metalligand cluster hosts. Chem. Rev. 2015, 115, 3012. (c) Kennedy, C. R.; Lin, S.; Jacobsen, E. N. The cation- $\pi$ interaction in small-molecule catalysis. Angew. Chem., Int. Ed. 2016, 55, 12596. (d) Neel, A. J.; Hilton, M. J.; Sigman, M. S.; Toste, F. D. Exploiting non-covalent $\pi$ interactions for catalyst design. Nature 2017, 543, 637. (e) Yamada, S. Cation $-\pi$ interactions in organic synthesis. Chem. Rev. 2018, 118, 11353.

(21) For a discussion of the relationship between thermodynamic parameters and attractive non-covalent interactions see: Williams, D. H.; Calderone, C. T. An enthalpic component in cooperativity: the relationship between enthalpy, entropy, and noncovalent structure in weak associations. J. Am. Chem. Soc. 2001, 123, 6262.

(22) See Supporting Information for details.

(23) For a discussion of the role of dispersion forces in cation- $\pi$ interactions see: Tsuzuki, S.; Mikami, M.; Yamada, S. Origin of attraction, magnitude, and directionality of interactions in benzene with pyridinium cations $J$. Am. Chem. Soc. 2007, 129, 8656.

(24) For a discussion of the role of electrostatics in cation- $\pi$ interactions see: Mecozzi, S.; West, A. P.; Dougherty, D. A. Cation- $\pi$ interactions in simple aromatics: electrostatics provide a predictive tool. J. Am. Chem. Soc. 1996, 118, 2307.

(25) For additional examples of tuning cation- $\pi$ interactions with extended aromatic motifs in enantioselective catalysis see: (a) Lin, S.; Jacobsen, E. N. Thiourea-catalysed ring opening of episulfonium ions with indole derivatives by means of stabilizing non-covalent interactions. Nat. Chem. 2012, 4, 817. (b) Bendelsmith, A. J.; Kim, S. C.; Wasa, M.; Roche, S. P.; Jacobsen, E. N. Enantioselective synthesis of $\alpha$-allyl amino esters via hydrogen-bond-donor catalysis. J. Am. Chem. Soc. 2019, 141, 11414.

(26) Additional support for the role of stabilizing interactions is offered by the observation that atropisomers of complex 7 , which are expected to be sterically dissimilar, exhibit equivalent performance in the hydrofunctionalization of alcohol 1. See SI for details.

(27) Epoxides 17 and 19 were obtained in $80 \%$ ee at $-40{ }^{\circ} \mathrm{C}$.

(28) For discussion of alkyl fluoride-cation interactions relevant to the case of product 14 see: Ferraris, D.; Cox, C.; Anand, R.; Lectka, T. C-F Bond activation by aryl carbocations: conclusive intramolecular fluoride shifts between carbon atoms in solution and the first examples of intermolecular fluoride ion abstractions. J. Am. Chem. Soc. $1997,119,4319$.

(29) For relevant cases of dynamic kinetic resolution in nickelcatalyzed cross-coupling reactions see: (a) Lin, X.; Sun, J.; Xi, Y.; Lin, D. How racemic secondary alkyl electrophiles proceed to enantioselective products in Negishi cross-coupling reactions. Organometallics 2011, 30, 3284. (b) Gutierrez, O.; Tellis, J. C.; Primer, D. N.; Molander, G. A.; Kozlowski, M. C. Nickel-catalyzed cross-coupling of photoredox-generated radicals: uncovering a general manifold for stereoconvergence in nickel-catalyzed cross-couplings. J. Am. Chem. Soc. 2015, 137, 4896.

(30) For discussion of homolysis of relevant alkylcobalt(IV) complexes see ref. $18 \mathrm{~b}, \mathrm{c}$.

(31) (a) Samsel, E. G.; Kochi, J. K. Radical chain mechanism for alkyl rearrangement in organocobalt complexes. J. Am. Chem. Soc. 1986, 108, 4790. For relevant radical chain mechanism in nickelcatalyzed cross-coupling reactions see: (b) Schley, N. D.; Fu, G. C. Nickel-catalyzed Negishi arylations of propargylic bromides: a mechanistic investigation. J. Am. Chem. Soc. 2014, 136, 16588.

(32) (a) Radical pair formation via the HAT: Sweany, R. L.; Halpern, J. Hydrogenation of $\alpha$-methylstyrene by hydridopentacarbonylmanganese(I). Evidence for a free-radical mechanism. J. Am. Chem. Soc. 1977, 99, 8335. (b) Ungvávy, F.; Markó, L. Reaction of $\mathrm{HCo}(\mathrm{CO})_{4}$ and $\mathrm{CO}$ with styrene. Mechanism of ( $\alpha$-phenylpropiony 1$)-$ and ( $\beta$-phenylpropionyl)cobalt tetracarbony1 formation. Organometallics 1982, 1, 1120.

(33) For relevant discussions see refs. 3, 5g, 6a,c.

(34) Lande, S. S.; Kochi, J. K. Formation and oxidation of alkyl radicals by cobalt(III) complexes. J. Am. Chem. Soc. 1968, 90, 5196. 
(35) For an excellent discussion of the activation parameters of the capture of diffusing alkyl radicals with metal complexes see: Koenig, T. W.; Hay, B. P.; Finke, R. G. Cage effects in organotransition metal chemistry: their importance in the kinetic estimation of bond dissociation energies in solution. Polyhedron 1988, 7, 1499.

(36) Enantio-determining capture of diffusing alkyl radicals with neutral cobalt(II) intermediates en route to alkylcobalt(III) complexes is unlikely because the magnitude of the differential activation enthalpy obtained for catalyst $\mathbf{8}$ in the reaction of alcohol $\mathbf{1}$ (see Table 3 ) is considerably larger than the activation enthalpy associated with this diffusion-controlled process (ca. $2 \mathrm{kcal} / \mathrm{mol}$, see: Tsou, T.-T.; Loots, M.; Halpern, J. Kinetic determination of transition-metal-alkyl bond dissociation energies: application to organocobalt compounds related to $\mathrm{B}_{12}$ coenzymes. J. Am. Chem. Soc. 1982, 104, 623).

(37) (a) Clark, R. D.; Caroon, J. M.; Repke, D. B.; Strosberg, A. M.; Bitter, S. M.; Okada, M. S.; Michel, A. D.; Whiting, R. L. Anti- hypertensive 9-substituted 1-oxa-4,9-diazaspiro[5.5]undecan-3-ones. J. Med. Chem. 1983, 26, 855. (b) Hewitt, P.; McFarland, M. M.; Rountree, J. S. S.; Burkamp, F.; Bell, C.; Proctor, L.; Helm, M. D.; O'Dowd, C.; Harrison, T. Preparation of oxoheterocyclylalkyl hydroxypiperidinylketones as ubiquitin-specific protease USP19 inhibitors useful in treatment of diseases. PCT Int. Appl. WO 2018/020242 A1, February 01, 2018.

(38) For recent computational studies of HAT from relevant metal hydrides to alkenes see: (a) Kim, D.; Rahaman, S. M. W.; Mercado, B. Q.; Poli, R.; Holland, P. Roles of iron complexes in catalytic radical alkene cross-coupling: a computational and mechanistic study. $J$. Am. Chem. Soc. 2019, 141, 7473. (b) Jiang, H.; Lai, W.; Chen, H. Generation of carbon radical from iron-hydride/alkene: exchangeenhanced reactivity selects the reactive spin state. ACS Catal. 2019, 9 , 6080 .

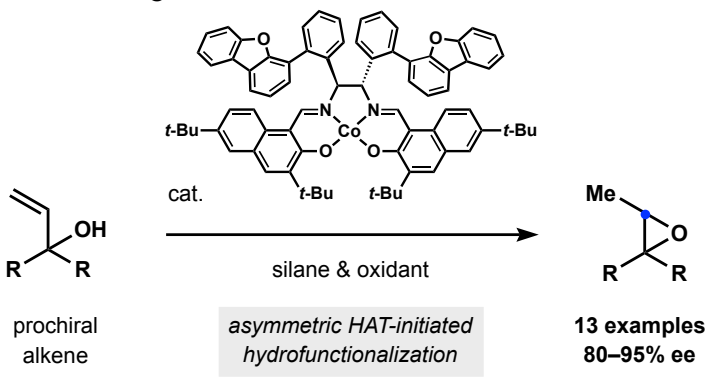

